\title{
Statistical Correlation on Internal Issues of Spinning Textile industry in Pakistan
}

\author{
Abdul Sattar Shah \\ Professor-IBA-University of Sindh-Jamshoro \\ Pir Roshah Shah Rashdi \\ Professor-MUSTARD \\ MUET Jamshoro \\ Dr.Muhammad Munir Ahmadani \\ Assistant Professor \\ Govt:College for Commerce \\ Hyderabad \\ Mr. Sarmad Rahat \\ Lecturer, Department of Economics \\ Shah Abdul Latif University Khairpur
}

\begin{abstract}
This research investigates the Statistical Correlation on Internal Issues of Spinning Data were collected from Primary as well as secondary sources It is a statistical research technique in decision making that is used for the selection of a limited number of tasks that produce significant overall effect. It separates the few major problems from the many possible problems. It is named after Vilfredo Pareto, a 19th-century Italian economist. It was revealed that Textile spinning sector detail of analysis performed for reducing a huge number of issues explored from textile industry of Pakistan in the era of trade liberalization. The research in this part of framework starts by conducting a survey of the textile industry of Pakistan for the collection of data through questionnaire consisted of the explored issues. The data collected through survey is then used to perform Pareto analysis and bring up the prioritized issues after reducing them by using statistical tool SPSS. Then statistical Correlation is performed on the prioritized issues reduced through Pareto analysis to find the level of relationship among these issues, so by solving one issue the other may routinely be solved.
\end{abstract}

Key Words:Statistical Correlation, Issues, Spinning

\section{Council for Innovative Research}

Peer Review Research Publishing System

Journal: International Journal Of Management \& Information Technology

Vol . 10, No 6

editorsijmit@gmail.com

www.jimit.com

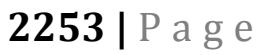

February, 04, 2015 


\section{Introduction}

Textile industry of Pakistan is broadly divided into many sectors that are Ginning, Spinning, Weaving, Knitting, Towel, Dying, Printing, Processing, Hosiery, Made-ups and Garments. As the first objective was concerned with understanding the current status of textile industry; in this connection a survey of the entire textile industry was conducted. A sample of 100 respondents was designed for conducting the research in Hyderabad, Kotri, Karachi, Faisalabad and Lahore region including the key integrated textile units to ensure full representation of all sectors. Further the above sectors of textile industry were lumped together into four major sectors as Spinning, Weaving (including Knitting), Processing (including; Dying Printing \& Bleaching), and Garments (including Made-ups, towel, Hosiery and other manufactured items) for compiling the qualitative information. The survey methodology included a combination of primary data that was generated through a questionnaire and intensive interviews with individuals connected to the industry to identify their internal issues, national issues, global issues and required remedial actions and the secondary data included journal articles, trade policies of Pakistan, news, and internet which were helpful for the second and the third objectives. For the accomplishment of second objective the graphs are used to explain the growth pattern of textile exports from the year 1980 to 2009 as the implementation of WTO on textile industry of Pakistan started from 1995 that was 100\% complete in 2005. Therefore the starting 14 years from 1980 to 1994 are considered as the time period with quotas, whereas the last 14 years from 1995 to 2009 are considered as the quota free era. In the third objective developing countries like China, India, Srilanka and Bangladesh are taken into account to analyze the effects of WTO on them. Here the information collected through the above mentioned secondary sources regarding the benefits of becoming the member of WTO and the problems associated with its implementation are highlighted.

Textile spinning sector detail of analysis performed for reducing a huge number of issues explored from textile industry of Pakistan in the era of trade liberalization. The research in this part of framework starts by conducting a survey of the textile industry of Pakistan for the collection of data through questionnaire consisted of the explored issues. The data collected through survey is then used to perform Pareto analysis and bring up the prioritized issues after reducing them by using statistical tool SPSS. Then statistical Correlation is performed on the prioritized issues reduced through Pareto analysis to find the level of relationship among these issues, so by solving one issue the other may routinely be solved.

The detail of the analysis performed to reduce and resolve the explored issues from the textile industry of Pakistan is discussed in the following sections:

\section{Issues of Textile industry of Pakistan}

The issues of textile industry of Pakistan as shown in figure 6-1 are divided into three categories:

- Internal Issues

- National Issues

- Global Issues

\section{Issues of Textile Industry of Pakistan}

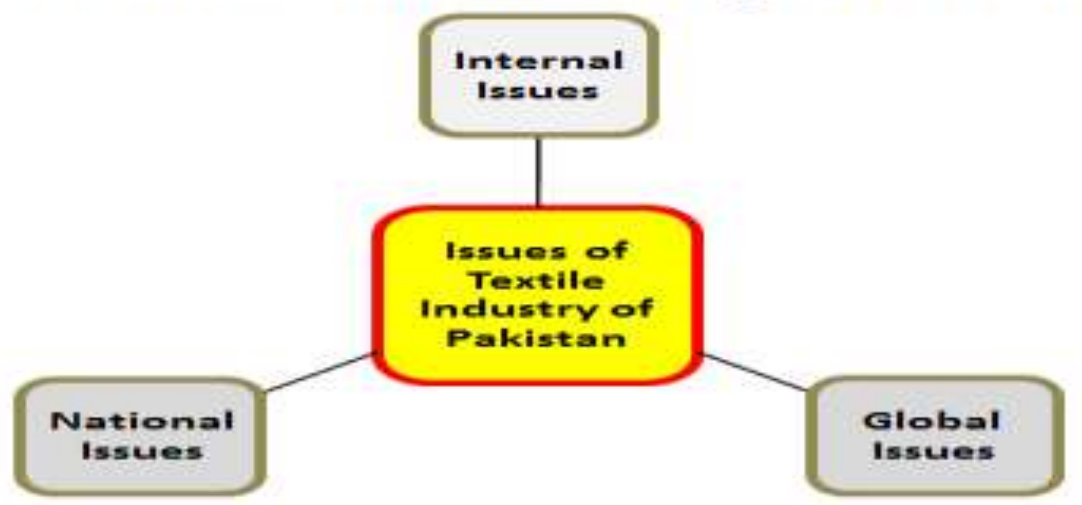

Figure 6-1 Issues of Textile industry of Pakistan

\subsubsection{Internal Issues}

The internal issues of the textile industry of Pakistan as shown in figure 6-3 are divided sector wise into four sectors:

- Issues of spinning

- Issues of weaving

- Issues of processing 


\section{INTERNAL ISSUES}

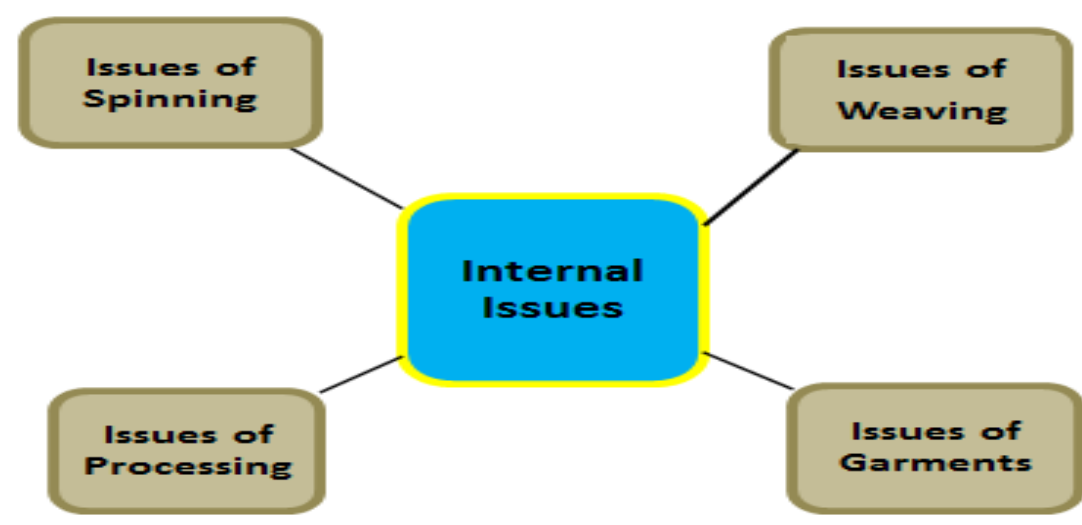

Figure 6-2 Internal Issues of Textile Industry of Pakistan

\subsection{1-1 Internal Issues of the Spinning Sector}

Initially there were about 7 issues in the Spinning Sector that are also presented in figure 6-3 below:

$1 \mathrm{CC}$ : Contaminated cotton is used in spinning

2 LQ: Low quality of yarn

3 IS: It is difficult to meet the International Standards

4 LR: Lower returns from selling yarn in International Markets

$5 \mathrm{SH}$ : Agriculturists are shifting from cotton to other cash crops

$6 \mathrm{HM}$ : Improper handling methods of cotton

7 CA Unable to benefit from the competitive advantage

\section{Issues of Spinning}

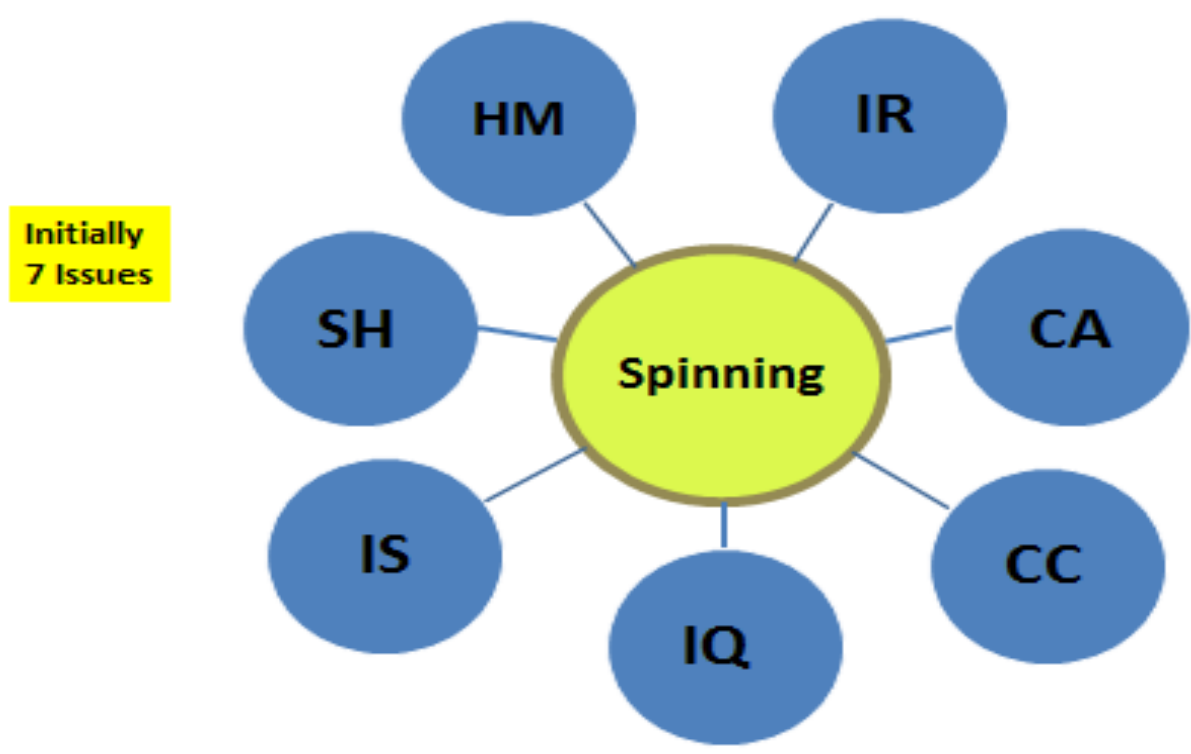

Figure 6-3: Issues of Spinning Sector

\subsection{1-2 Pareto Analysis on the issues of Spinning Sector}

Pareto Analysis was performed on the issues of spinning sector by using SPSS and the output is shown in Pareto chart 6 1 below: 


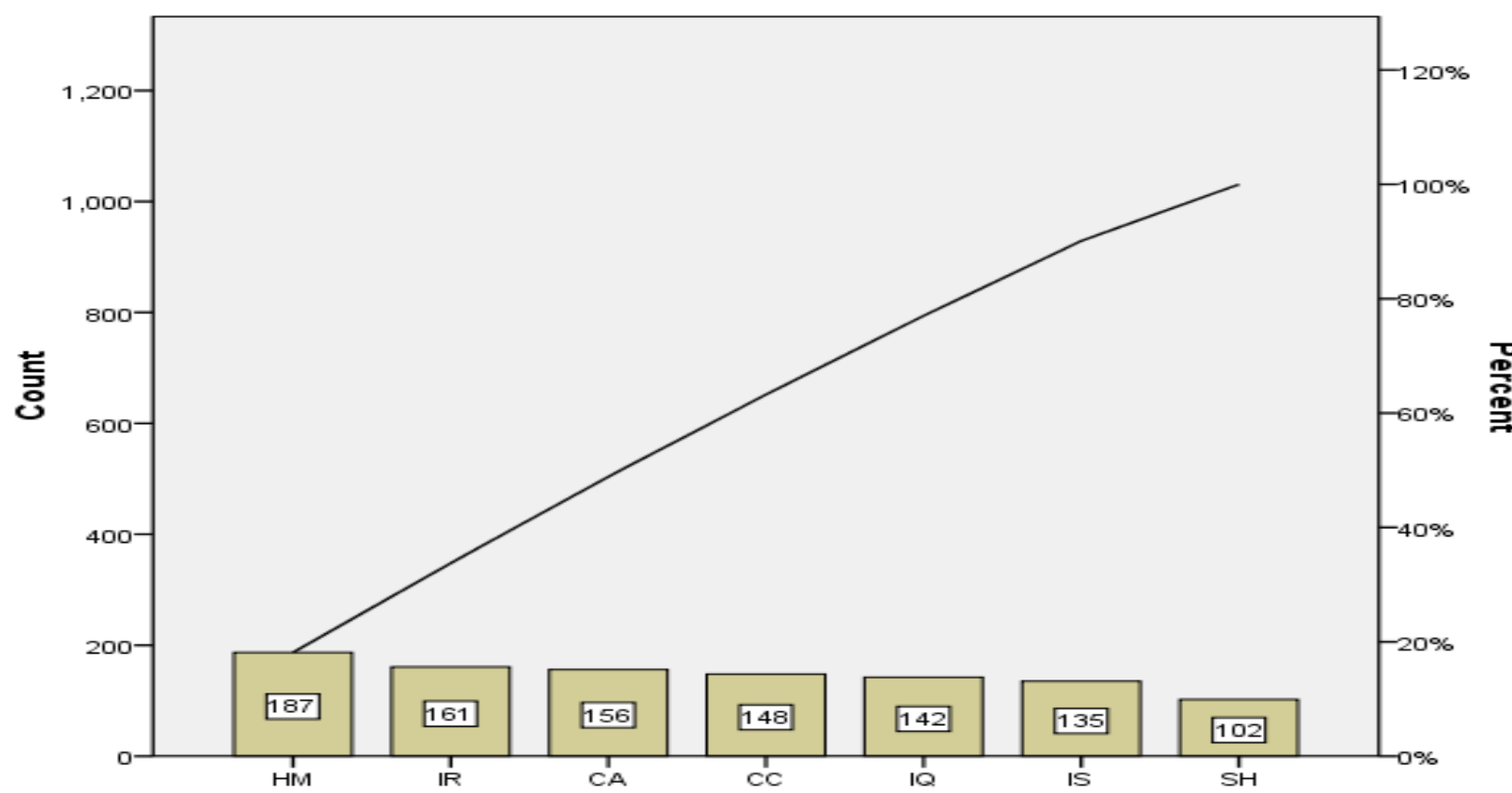

Pareto Chart 6- 1: Pareto Analysis on the issues of Spinning Sector

\subsection{1-3 Result of Pareto Analysis on the issues of Spinning Sector}

Initially as the issues of Spinning Sector were 7, after performing Pareto analysis the output shows total counts equivalent to 1031. As the Pareto analysis is a technique used in decision making to highlight the prioritized issues, so that by solving them overall problems (about $80 \%$ ) may be solved. In this connection it is suggested to take about $80 \%$ to solve the overall issues but here the $80 \%$ is between fifth and issue. Therefore it was decided to take about $76 \%$ through which 5 issues may be selected as shown in the Diagram 6-1 and also shown the remaining 5 issues in figure: 6-4 below for further making decisions. However 6 issues were equal to 927 which were about $90 \%$.
- Total (Counts):
$1031(100 \%)$
- Suggested:
- $\quad$ Taken (5 Issues):
$792(76.81 \%)$

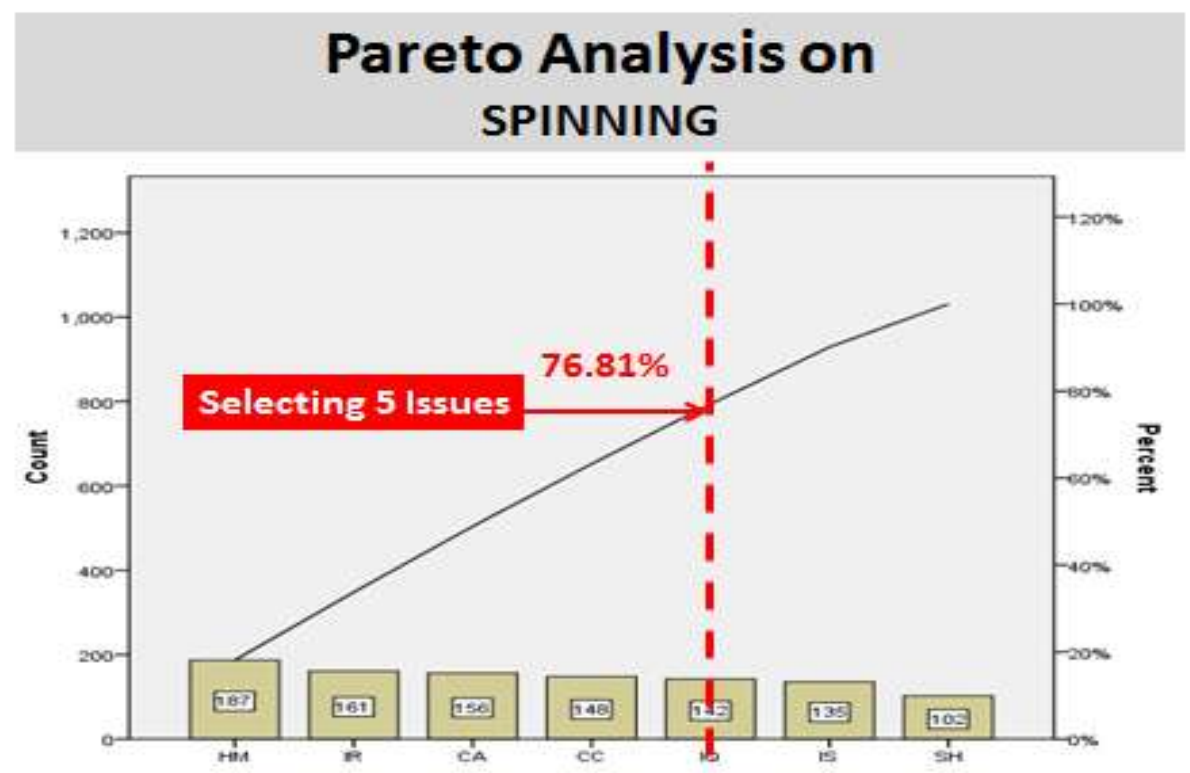

Pareto Chart 6-2: Selection from Pareto Chart 
Therefore, 5 issues are selected from spinning sector that are also presented in figure 6-5 below:

$1 \mathrm{CC}$ : Contaminated cotton is used in spinning

2 LQ: Low quality of yarn

3 LR: Lower returns from selling yarn in International Markets

$4 \mathrm{HM}$ : Improper handling methods of cotton

$5 \mathrm{CA}$ : Unable to benefit from the competitive advantage

\section{After
Pareto Analysis Issues of Spinning}

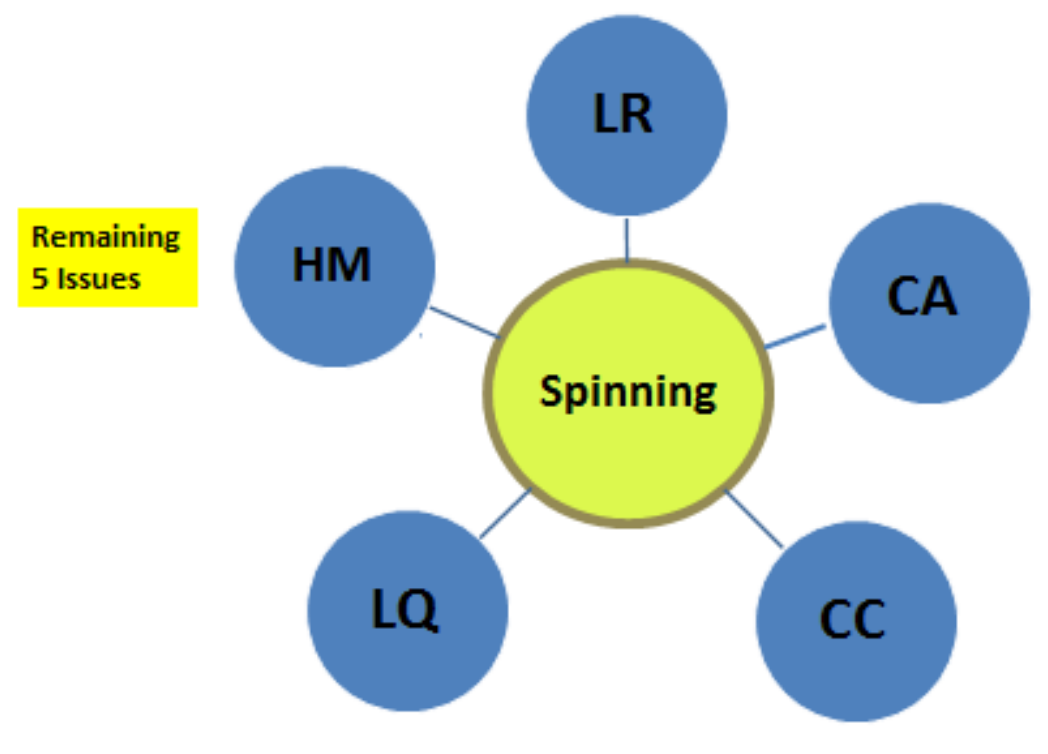

selected issues of spinning sector after Pareto analysis

Conclusion: To solve the problems associated with textile industry that is experiencing a decline in exports country's Government plays an important role. In case of industrial problems associated with trade, Government attempts to solve the issues through trade policy measures. The second body to solve the issues is industry that by making innovative decisions and through developing strategies may provide the means to resolve them. Finally, the university may further attempt the researchers to conduct research for the prosperity of industry and economic development of Pakistan by providing appropriate ways to solve the issues.

1. Rafi K. S., 2005, "Impact of WTO on the Patterns of Trade in Textile \& Clothing”, Journal of Management and Social Sciences, Vol. 1, No. 2, (Autumn 2005) 204-226

2. Sasi A, 2005, "Asian Textile Nations to Join Hands to Rule Global Markets", Business Line, International Edition, Financial Daily from the Hindu Group of Publications Sunday, Sep. 4, 2005.

3. Sheikh H, 2005, "Pakistan bed linen exports: Problems \& Prospects ", Pakistan Textile Journal

4. Viqar S, 2005, " Brand Development and the Role of Designers in WTO ", Pakistan Textile Journal

5. Weeraratne B, 2005,"Labour Standards and International Trade : The Case of EU GSP Concessions to Srilanka", Working Paper Series No: 8.

6. Kashif R. S, 2005, "Impact of WTO on the Patterns of Trade in Textile \& Clothing", Journal of Management and Social Sciences, Vol. 1, No. 2, (Autumn 2005) 204-226

7. Baig M, 2004, "Global scenario of textiles and position of Pakistan ", Pakistan Textile Journal.

8. Haverson K, 2004, "China's WTO accession: Economic, Legal and Political Implications", Journal Contents, (Publication Students Homepage).

9. Kelegama, S., 2004, "Ready-Made Garment Industry in Sri Lanka: Facing the Global Challenge", Institute of Policy Studies, Colombo.

10. Council Regulation (EC) No 980/2005 of 27 June 2005, "Applying a scheme of generalised tariff preferences", Official Journal L 169, 30/06/2005 P. $0001-0043$. 
11. MTDF (Medium term development Framework 2005 - 10) Planning Commission Government of Pakistan, May 2005.

12. United States International Trade Commission (USITC) 2004, Textile and Apparel: Assessment of the Competitiveness of Certain Foreign Suppliers to the U.S. Market, Vol. 1, USITC, Washington, D.C.

13. RIS (2004). South Asia Development and Cooperation Report 2004, Research and Information System for NonAligned and Other Developing Countries, New Delhi.

14. UNCTAD (2003), "The African Growth and Opportunities Act: A Preliminary assessment", (UNCTAD/ITCD/TSB/2003/1).

15. IPS (2003), Sri Lanka: State of the Economy - 2003, Institute of Policy Studies, Colombo, Sri Lanka. 